\title{
PERFIL DO PESSOAL EMPREGADO FORMALMENTE NO SUBSETOR DE HOSPEDAGEM NOS MUNICÍPIOS DE CALDAS NOVAS, GOIÂNIA, PIRENÓPOLIS E RIO QUENTE ${ }^{1}$
}

\author{
PROFILE OF THE STAFF EMPLOYED IN THE SUBSECTOR OF \\ LODGING IN THE CITIES OF CALDAS NOVAS, GOIÂNIA, \\ PIRENÓPOLIS AND RIO QUENTE
}

\author{
PROFIL DU PERSONNEL EMPLOYÉ FORMELLEMENT DANS LE \\ SOUS-SECTEUR DE LOGEMENT DANS LES VILLES DE CALDAS \\ NOVAS, GOIÂNIA, PIRENÓPOLIS ET RIO QUENTE
}

\author{
Gisélia Lima Carvalho \\ Professora Efetiva do Instituto Federal de Educação Tecnológica de Goiás/IFG. \\ Campus de Goiânia - Brasil \\ Rua 75, n 46, Centro. CEP: 74055-110. Goiânia - GO. \\ E-mail: glc@ifg.edu.br
}

\begin{abstract}
Resumo
O presente texto trata da temática da mão de obra formal ocupada em Atividades Características do Turismo (ACT) em municípios do Estado de Goiás, a partir da descrição e da análise dosmeios de hospedagem. Pretende-se mostrar a relevância social e econômica desse subsetor do turismo, de modo a compreender alguns de seus impactos. Goiânia, Pirenópolis, Caldas Novas e Rio Quente, quatro dos importantes destinos turísticos do estado, fazem parte dorecorte geográfico deste estudo que tem como escala temporal o período de 2000 a 2008 e como fonte de pesquisa a base de dados da Relação Anual de Informações Sociais (RAIS), do Ministério do Trabalho e Emprego (MTE).
\end{abstract}

Palavras-chave:Empregos Formais; Meios de Hospedagem;Municípios Turísticos; Estado de Goiás.

\begin{abstract}
The present paper addresses the issue of formal workforce engaged in Tourism Characteristic Activities (ACT) in the municipalities of the State of Goiás, from the description and analysis of the lodging facilities. We intend to show the social and economic relevancy of this tourism subsector in order to understand some of its impacts. Goiânia, Pirenópolis, Caldas Novas and Rio Quente are among the four important touristic destinations of the state, and they take part in the geographic division

\footnotetext{
${ }^{1} \mathrm{O}$ presente artigo é parte dos resultados finais da pesquisa sobre a caracterização e a análise do perfil da mão de obra ocupada no turismo do estado de Goiás, a partir de 2000, realizada pela autora no Instituto Federal de Educação Tecnológica de Goiás (IFG), com financiamento da Fundação de Amparo à Pesquisa do Estado de Goiás (FAPEG).
} 
of this study which has as a temporal scale the period from 2000 to 2008 , and as the source of research the database of the Annual Social Information Report (RAIS) from the Ministry of Labor and Employment (MTE).

Key words: Formal Jobs, Lodging Facilities, Touristic Municipalities, State of Goiás.

\section{Résumé}

Ce document aborde la question de main-d'oeuvre engagée dans les Activités Caractéristiques de Tourisme (ACT) dans les villes de Goiás, a partir de la description et de l'analyse de logement. Il est destiné à montrer la pertinence sociale et économique du sous-secteur du tourisme afin de comprendre certains de sés impacts. Goiânia, Pirenópolis, Caldas Novas et Rio Quente sont les quatre destinations touristiques qui font partie de cette étude géographique dont l'échelle de temps qui comprend la période de 2000 à 2008 et comme source de recherche la base de données de la Relation Annuelle des Informations Socialles (RAIS) du Ministère du Travail et de 1'Emploi (MTE).

Mots-clés: emplois formels, logement, villes touristiques, L`État de Goiás.

\section{Introdução}

O impacto econômico da atividade turísticaem municípios resulta da ampliação das fontes de geração de renda e emprego, da entrada de divisas edo aquecimento das outras atividades econômicas, pelo seu efeito multiplicador. Os meios de hospedagem constituem uma das principais bases desse processo, posto que a demanda por bens e serviços resulta,justamente, na criação, ampliação e/ou melhoramento desses equipamentos que, tão logo a atividade se desenvolve, expressam-se de imediato na paisagem do destino, transformando aimagem de outrora.Desse modo, a hotelariapassa a ser o elemento visualmente presente no espaço e o maior ou um dos maiores focos de atração de emprego na economia de locais turísticos. É o que acontece nos municípios de Rio Quente, Caldas Novas e Pirenópolis, cuja existência de hospedagens se dá em função de uma demanda de não residentes que viajam por lazer ou em função de negócios. No caso desses destinos citados, a demanda se dá, sobremaneira, por lazer. No entanto, há municípios que, dada sua condição urbana e sua localização,têm em sua estrutura equipamentos hoteleiros de forma expressiva, embora nem sejam reconhecidos como turísticos pelo público viajante, como é o caso da cidade de Goiânia.

Mediante o exposto, o que se pretende neste artigo é avaliar o impacto dos equipamentos de hospedagem na economia de quatro dos principais municípios 
turísticos do estado de Goiás - Caldas Novas, Goiânia, Rio Quente e Pirenópolis - a partir do estudo dos empregos formais oferecidos por esse segmento. Com isso, objetiva-se averiguar qual é a relevância desse subsetor frente a outras atividades do turismo no contexto da economia local e verificar em que medida estes equipamentosestão gerando empregos, destacandoseus níveis, seu quadro evolutivo de 2000 a 2008, além do perfil dos empregados pelas variáveis gênero, idade, escolaridade e rendimento. Com este balizamento, busca-se traçar um panorama do setor de hospedagem nesses municípios a fim de fornecer subsídios que possam diagnosticar as necessidadesreferentes ao mercado de trabalho no turismo.

\section{Impactos Econômicos do Turismo e o Subsetor de Hospedagem}

Dimensionar os impactos econômicos das atividades turísticas não parece ser uma tarefa fácil, uma vez que seus efeitos se referem não só a emprego e renda locais advindos dos usos e consumos da demanda turística. Avaliar o nível dos impactos do turismo pelas receitas e despesas reduz o campo da compreensão do fenômeno, assim como ressaltam Cooper et al. (2007). Para estes autores, o impacto econômico deve ser medido também pelas "receitas governamentais e o ingresso de divisas estrangeiras em qualquer economia”. A renda do turismo em uma localidade resulta da injeção de gastos com hospedagem, alimentos e bebidas,compra de produtos e serviços que melhoram a experiência do turista no destino enquanto formas de lazer e/ou negócios. "Os turistas começam gastando dinheiro em estabelecimentos turísticos de linha de frente, como hotéis, restaurantes, táxis e depois isso se espalha pelo resto da economia." (COOPER et al. 2007, p. 179).

Assim, antes de tentar mensurar o impacto do turismo é necessário "examinar os diferentes aspectos da economia que são afetados pelas despesas turísticas." (COOPER et al. 2007, p. 177). Isto se faz necessário visto que o resultado do turismo se mostra a partir do efeito em cascata na economia local. Ou seja, efeitos diretos, indiretos e induzidos, que se desdobram no espaço turístico, eclodindo no tão propalado "conceito de multiplicador", que se baseia no reconhecimento de que todas as vendas de uma firma qualquer exigem compras de outras empresas dentro da economia local, demonstrando que todos os setores da economia são interdependentes,o que quer dizer 
que "qualquer mudança nas despesas turísticasproduzirá uma mudança no nível de produção, renda familiar, emprego, receitas do governo e fluxos de moeda estrangeira onde for o caso." (COOPER et al. 2007, p. 181).

Estes elementos são rapidamente sentidos pela população quando a atividade é plenamente desenvolvida. No entanto, não é o que acontece em todos os municípios turísticos brasileiros, sobretudo nos de menor escala geográfica. Muitas vezes, o que melhor se expressa é o nível de impacto na paisagem em forma de empreendimentos turísticos e, sobremaneira, no setor hoteleiro, como é o caso dos municípios goianos de Caldas Novas, Rio Quente e Pirenópolis. O caso de Rio Quente, por se tratar de um município que nasce a partir da atividade turística, os empreendimentos dispostos na paisagem se dão de forma altamente concentrada, representando um grande impacto visual (Figuras 01 e 02). Em Pirenópolis, embora de forma bastante dispersa,os hotéis e pousadas se localizam em toda a área tombada, observando-se uma concentração do seu número nas ruas que dão acesso aos atrativos naturais, conforme ressaltado por Godinho e Oliveira (2010).

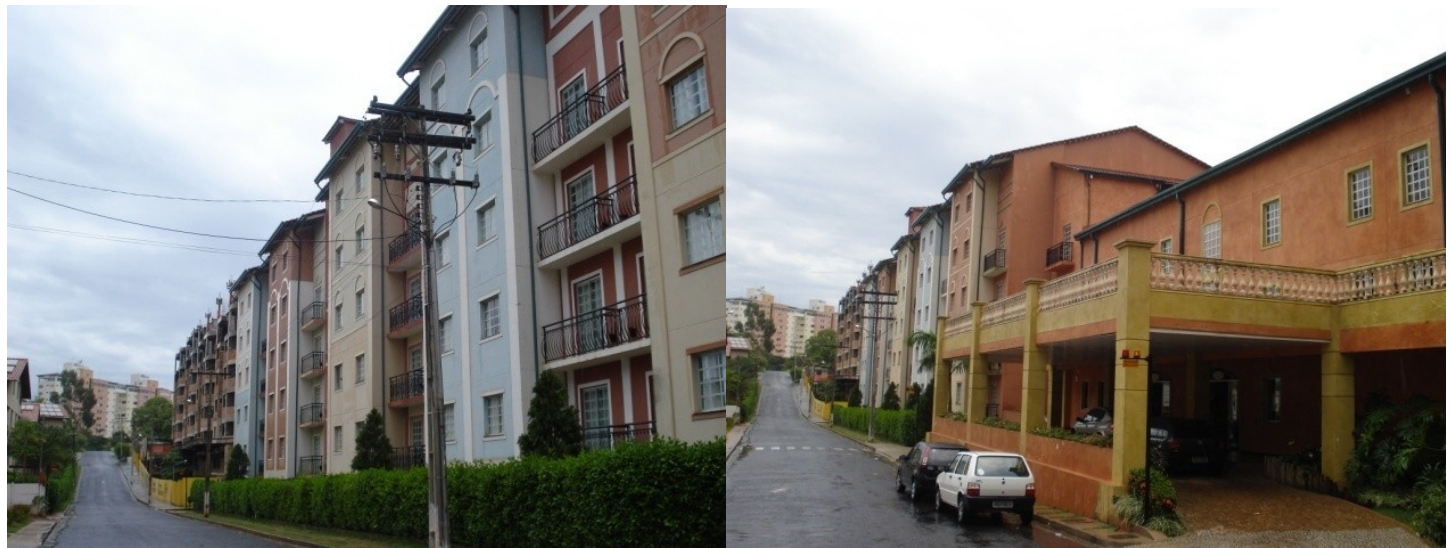

Figura 01

Impacto na paisagem em função dos empreendimentos hoteleiros do município de Rio Quente. Foto: Carvalho (2008).

Os equipamentos de hospedagem são, nesses municípios, o maior vetor dos impactos sob forma de geração de empregos que atraem mão de obra com níveis diversos de qualificação. A atividade turística, para seu funcionamento, depende, em grande parte, do fator humano, o que implica dizer que, em função dessa dependência, deve favorecer a criação de empregos. Mathieson e Wall (1982, p. 77 apud OMT, 2001, p. 205) distinguemtrês tipos de empregos gerados pelo turismo: 
1. Direto - resultado dos gastos dos visitantes em instalações turísticas, como hotéis; 2. Indireto - ainda no setor turístico, mas não como resultado direto dos gastos do turismo; 3. Induzido - resultado dos gastos dos moradores devido às entradas procedentes do turismo.

Os empregos diretos sãonormalmente os contabilizados na análise do impacto da atividade turística. Segundo a Organização Mundial do Turismo (OMT), historicamente, esses empregos eram constituídos, sobretudo, de pessoal menos qualificado, procedente de outros setores da economia (principalmente o primário), sem contrato de trabalho e com tempo parcial. Assim, pode-se dizer que o setor de turismo era caracterizado pela não profissionalização. Isso ocorria com maior frequênciano setor de hospedagem, que sempre demandou serviços como o de camareira, por exemplo, que, a priori, não requer uma qualificação, já que se assemelha aos serviços domésticos.

Todavia, esta realidade tem mudado com os anos, haja vista a significativa exigência por mão de obra qualificada. Segundo a Pesquisa Nacional por Amostra de Domicílios, realizada pelo Instituto Brasileiro de Geografia e Estatística - PNAD/IBGE -, “em 2005,o setor de turismo ocupou aproximadamente 4,5 milhões de pessoas, respondendo por mais de $5 \%$ do total dos postos de trabalho existentes naquele ano" (LARENTES; MIYASHIRO, 2007,p.24). De acordo com a pesquisa dos autores supracitados, entre os segmentos que compõem o setor de turismo, os maiores responsáveis pela geração de postos de trabalho naquele ano foram o de alimentação (exclusive os ambulantes), com 53,9\%; o detransportes rodoviários de passageiros, com $31,2 \%$, eo de alojamento (hotéis, pousadas e similares), com 10,6\%. Os demais, que somam 4,3\%, estavam empregados nos segmentos como transporte aéreo,agências de viagem, organizadores de viagens e aluguel de veículos.

O número de trabalhadores formais empregados em Atividades Características do Turismo no estado de Goiás passou de 35.736, em 2000, para 50.499, em 2004, e para 55.300, em 2008, segundo a Relação Anual de Informações Sociais (RAIS/MTE) ${ }^{2}$, representando um crescimento de, respectivamente, $26,87 \%$ e 9,09\% no período. Esses números ainda são muito tímidos se comparados à média de crescimento no Brasil que

\footnotetext{
${ }^{2}$ A RAIS- Relação Anual de Informações Sociais- "é um Registro Administrativocriado pelo Decreto $\mathrm{n}^{\mathrm{o}} 76.900 / 75$, com declaração anual e obrigatória a todosos estabelecimentos existentes no território nacional". Suas informações são captadas no mercado de trabalho formal em todo o Brasil, relativo a todas as atividades econômicas e referem-se somente "aosempregados celetistas, estatutários, avulsos, temporários, dentre outros". Por essa base pode-se conhecer o perfil e a situação dos trabalhadores, identificando elementos como remuneração, grau de instrução,ocupação, nacionalidade etc.
} 
tinha, em 2000, 1.724.963 trabalhadores com contratos de trabalho nas atividades de turismo. Este número teve um ótimo crescimento, passandode 78\%, em 2004, contabilizando 2.188.980 empregados. Já em 2008, registrou-se um leve crescimento no setor, chegando a 2.487.510empregados, representando um crescimento de $13, \%$. Neste último período, o crescimento foi semelhante ao de Goiás.

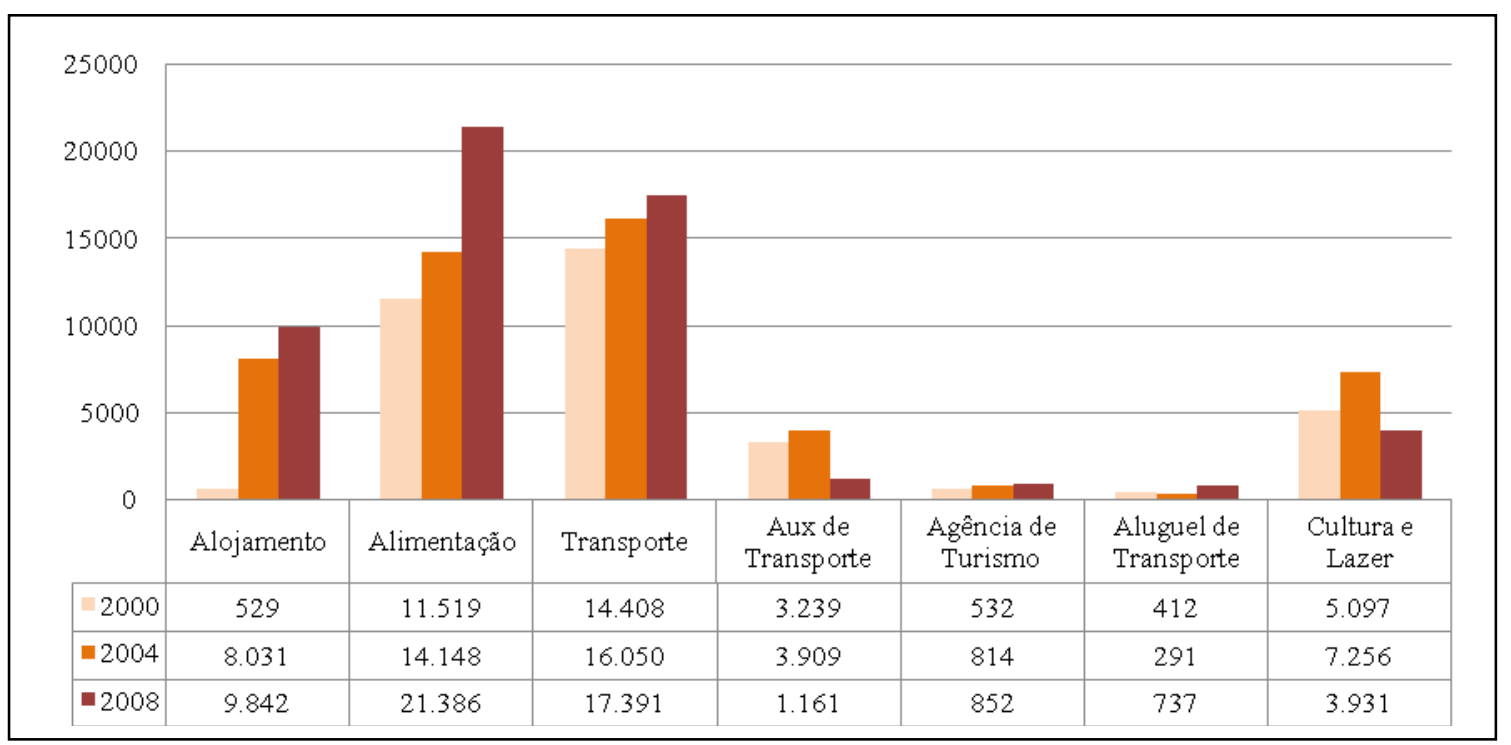

Figura 03: Evolução do número de empregados formais em atividades por características do turismo - Goiás (2000, 2004 e 2008)

Nos municípios turísticos aqui enfocados,pode-se perceber que as $\mathrm{ACT}^{3}$, em geral, têm tido uma evolução considerável no período de 2000 a 2008, com destaque maior para os segmentos de alimentação, transportes e alojamento (Figura 03). Os números maiores nos dois primeiros segmentos são representativos porque, na somatória, o município de Goiânia contribui para a elevação dos números desses dois setores.Se considerados os demais municípios, os dados de maior destaque dizem respeito ao setor de hospedagem, que representa o maior empregador no turismo nos municípios de Caldas Novas, Rio Quente e Pirenópolis. Faz-se necessário ressaltar o segmento de hospedagem que, embora com menos destaque quando se consideram as ACT,representa um importante vetor de alocação de mão de obra nos municípios turísticos quando se trata de serviços essencialmente turísticos ${ }^{4}$.

${ }^{3}$ As Atividades Características do Turismo (ACT) são compostas por um conjunto de categorias que obedece à Classificação Nacional de Atividades Econômicas - CNAE -, tais como alojamento, alimentação, agências de viagem, transporte, auxiliares do transporte não reconhecidas como preferentemente turísticas, aluguel de veículos, cultura e lazer. (IPEA, 2008).

${ }^{4}$ É justo alertar que muitas das ACT não são exclusivamente turísticas, mas são também parte 
Conforme ressaltam Larentes e Miyashiro (2007,p.83):

A ascensão da atividade turística em diferentes localidades do Brasil e, especialmente, a expansão de empreendimentos hoteleiros de médio e grande porte também influenciam a busca de novos padrões ou perfis de trabalhadores e o aumento das exigências de qualificação profissional.

O subsetor de hospedagem no Brasil apresenta especificidadesconforme a região geográfica. Segundo dados da RAIS/MTE, em 2005 este subsetor se apresentava da seguinte forma:

1. O ramo de alojamento no Brasil emprega formalmente em torno de 227 mil pessoas; 2. Dos cerca de 21,4 mil estabelecimentos que compõem o segmento no Brasil, quase $80 \%$ estão situados em áreas não metropolitanas e cerca de $20 \%$ em regiões metropolitanas; 3 . A maior concentração dos alojamentos - $45 \%$ - está na região Sudeste. No Nordeste estão instalados $21 \%$ do total de estabelecimentos, percentual aproximado do verificado na região Sul. No Centro-Oeste encontram-se cerca de $10 \%$, e na região Norte apenas 4,8\%. (RAIS/MTEapud LARENTES; MIYASHIRO, 2007, p. 28).

Atrelado a este panorama espacial e econômico dos meios de hospedagem no Brasil, os autores citados alertam para uma realidade recorrente em países centrais do capital, onde o turismo "caracteriza-se pelo emprego degrande quantidade de força de trabalho imigrante, clandestina e subcontratada" e alertam quenoBrasil uma das marcas do setor é o "trabalho sem registro, temporário e extenuante, de trabalhadorescom baixa escolaridade, com pouco ou nenhum acesso a qualificação profissional" (LARENTES; MIYASHIRO, 2007, p. 21). Cabe questionar aqui qual é a situação dos trabalhadores empregados no setor de hospedagem no estado de Goiás, tendo como foco de análise quatro de seus principais municípios turísticos.

\section{Características dos Trabalhadores Formais dos Meios de Hospedagem nos Municípios de Goiânia, Caldas Novas, Rio Quente e Pirenópolis}

Pretende-se, neste item, traçar um perfil dos empregados com carteira de trabalho assinada nos meios de hospedagem ${ }^{5}$. Para tanto, serão abordadas suas

\footnotetext{
fundamental dos serviços básicos da população residente nos destinos, como os segmentos de transporte, restaurantes, cultura e lazer, por exemplo. O contrário disso são os casos dos alojamentos, das agências de viagense aluguel de transportesque tem no consumo dos não residentes sua parte mais importante, conforme ressaltam Zomboni e Camargo (s/d).

${ }^{5}$ Para saber mais resultados sobre empregos formais no turismo nos municípios turísticos do estado de Goiás, consultar Carvalho (2011).
} 
principais características em relação às seguintes variáveis: gênero, faixa etária, nível de escolaridade e média de rendimento em salários mínimos. Os dados aqui apresentados são referentes apenas ao setor de hospedagem, composto por hotéis, pousadas e similares, com base na RAIS/MTE, coletados segundo quatro municípios turísticos goianos, escolhidos a partir dos seus desempenhos na categoria, frente aos demais subsetores do turismo. Como se pode perceber no Mapa dos Municípios Indutores do Turismo (MIDTUR) sobre as características dos empregos formaisem relação às atividades ligadas ao turismo, nos municípios de Rio Quente, Caldas Novas, Pirenópolis, Alto Paraíso e Goiás, o setor de hospedagem é o responsável pela maior parte dos postos de trabalho formais. Goiânia e Aruanã, no grupo do MIDTUR,comportam-se de modo diferente (Figura 04). Aquela, como capital do estado, apresenta a maior diversificação nos serviços turísticos, o que, por sinal, reduz o percentual dos empregados no setor de hospedagem quando posta ao lado de alguns municípios, mas assegura, no seu montante, o maior número de registros do estado. 


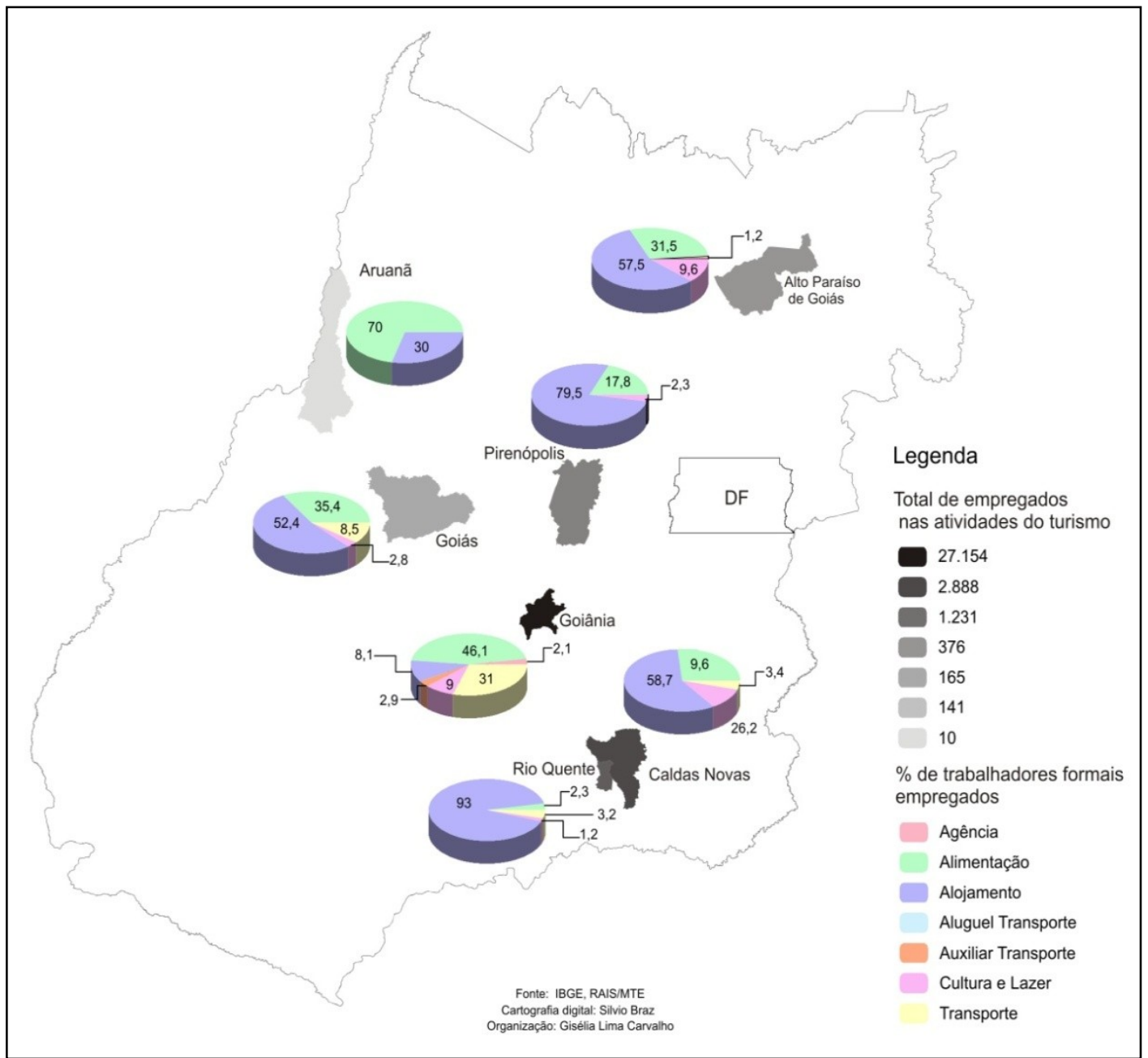

Figura 04: Goiás - Características dos empregados formais em ACTs nos municípios indutores do turismo (2008)

O município de Goiânia, em 2008, registrava o maior número de empregados como carteira assinada no setor de hospedagem (2.224), seguido de Caldas Novas (1.694), Rio Quente (1.147) e Pirenópolis (299), conforme demonstra aFigura 05 a seguir.

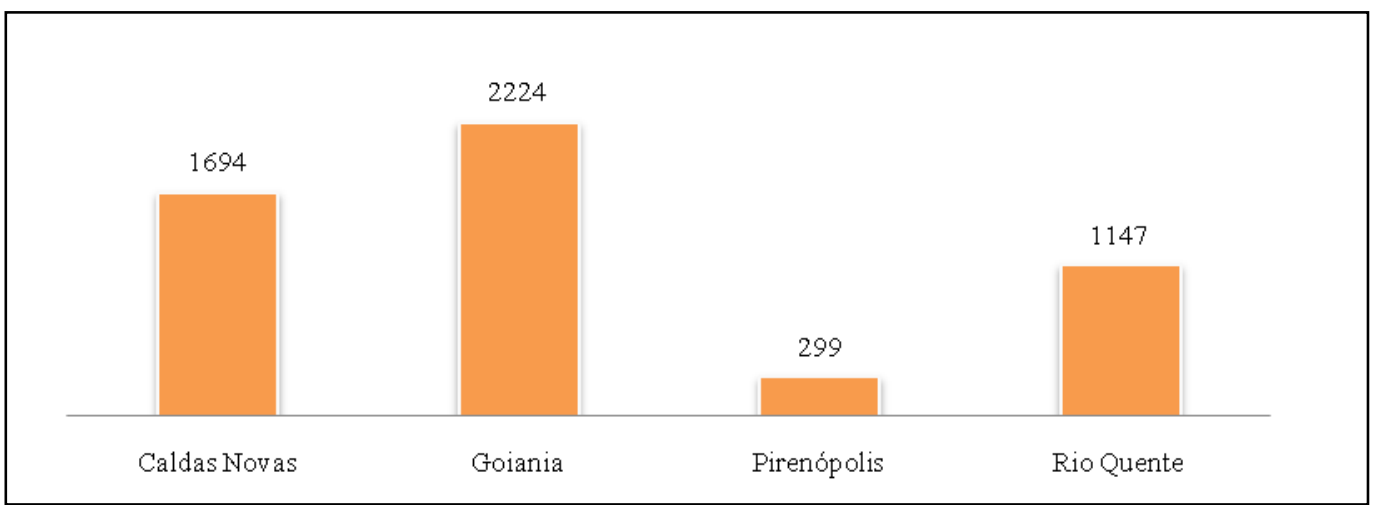

Figura 05: Total de empregados formais nos meios de hospedagem em 2008. 
Desses empregados, tenta-se aqui sintetizar os seus perfis na iminência de traçar um quadro com suas situaçõesem relação às seguintes variáveis:idade, sexo, escolaridade e renda. As questões relativas ao mercado de trabalho merecem atenção no sentido detentar compreender sua dimensão e trajetória, considerando suas especificidades e as desigualdades implícitas em todas as relaçõesdetrabalho que, numa perspectiva geográfica, são expressas na organização da paisagem dos lugares.

\section{Faixa Etária}

A série dos gráficos a seguir demonstra a evolução da faixa etária dos empregados celetistas do setor de hospedagem nos municípios turísticos entre 2004 e 2008 (Figuras 06, 07, 08 e 09).

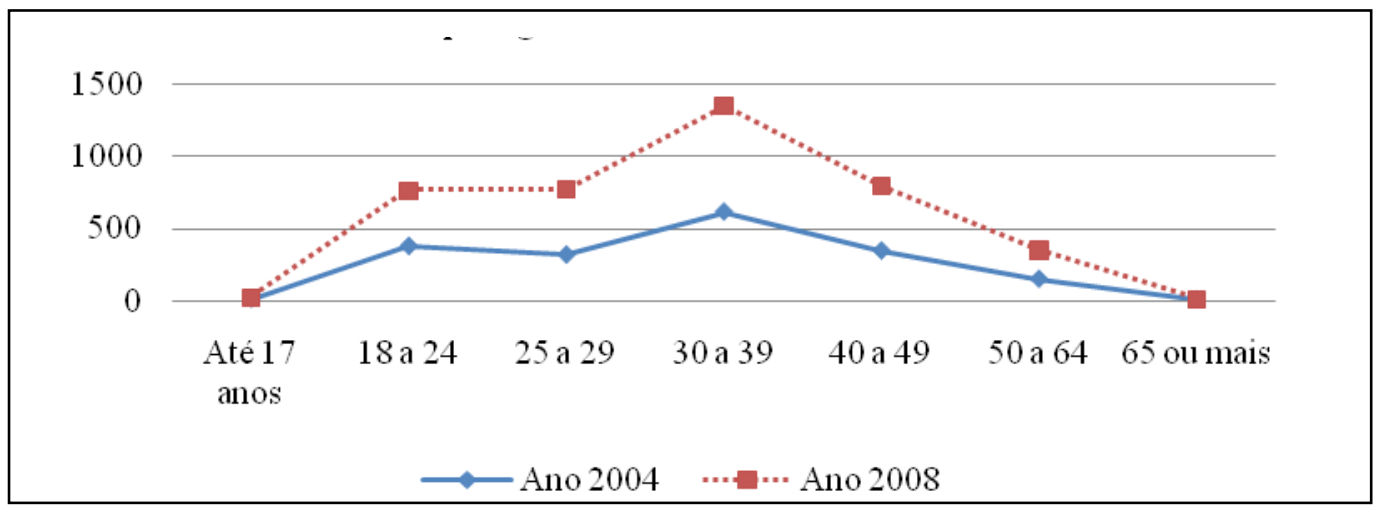

Figura 06: Evolução da faixa etária dos empregados do subsetor de hospedagem em Goiânia - 2004 a 2008

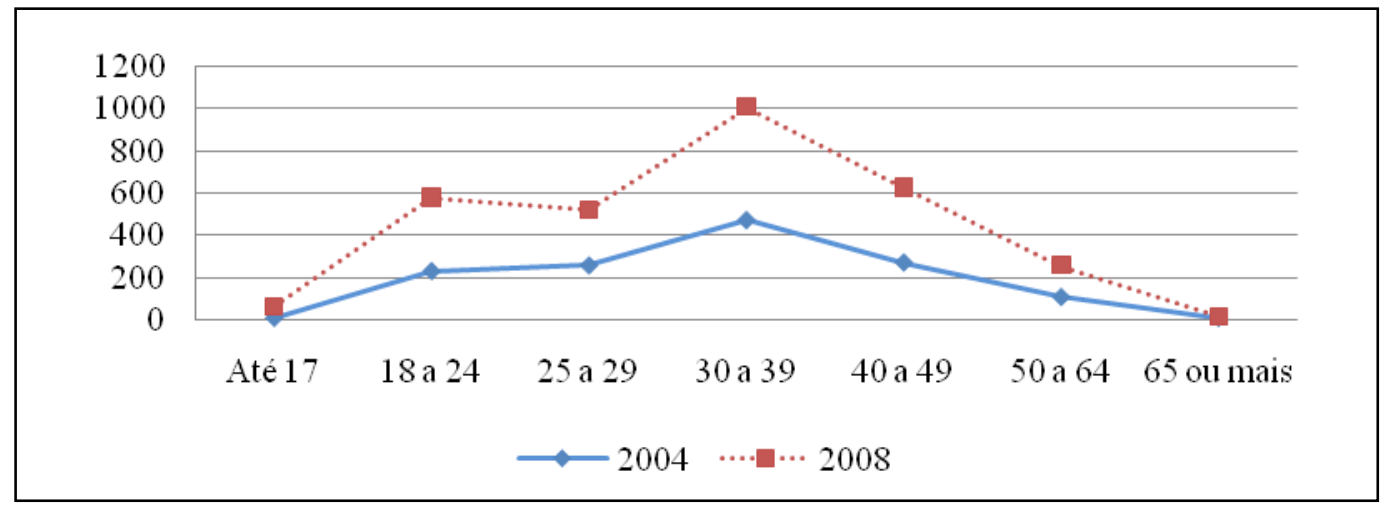

Figura 07: Evolução da faixa etária dos empregados do subsetor de hospedagem em Caldas Novas - 2004 a 2008. 


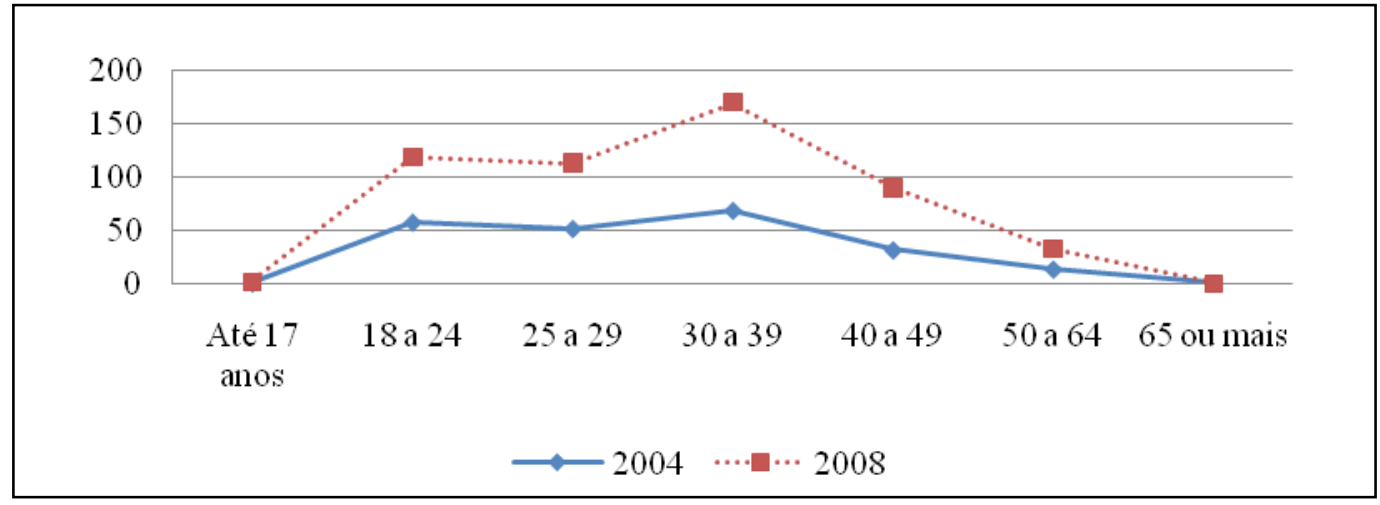

Figura 08: Evolução da faixa etária dos empregados do subsetor de hospedagem em Pirenópolis - 2004 a 2008.

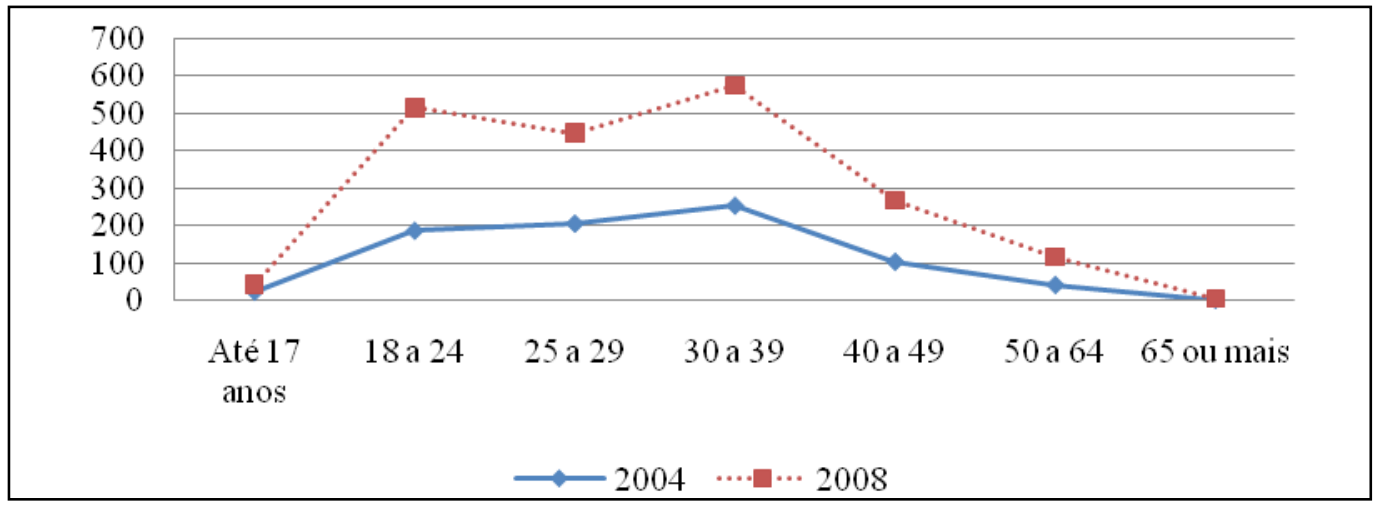

Figura 09: Evolução da faixa etária dos empregados do subsetor de hospedagem em Rio Quente - 2004 a 2008.

Nota-se que, nos municípios de Goiânia, Caldas Novas e Pirenópolis, há predominância de empregados na faixa etária de 30 a 39 anos. Mas as faixas entre 18 a 24, 25 a 29 e 40 a 49 também se mostram presentes em proporção semelhante em todos os municípios e anos. No município de Rio Quente, há uma diferença nos dados, já que há prevalência de três faixas de idade, que vão dos 18 aos 39 anos, em todos os anos pesquisados, sendo possível verificar que, neste município, há uma proporção deempregados mais jovens que nos demais.

Em relação ao grupo de trabalhadores com idade acima de 50 anos, todos os municípios têm em comum umreduzido número. Do mesmo modo, o perfil etário dos empregosneste segmento não se alterou de 2004 para 2008, demonstrando relativa homogeneidade em todo o conjunto dos gráficos. Wegrzynovski (2007)afirmouque, no 
Brasil, a maioria dos trabalhadores do turismo temmais de 25 anos e que o setor emprega bemmenos jovens que os demais setores da economia. Segundo sua pesquisa, a média de idade dos trabalhadores no setor é de 35,3 anos.

\section{Gênero}

A figura 10a seguir apresenta informações sobre a distribuição do gênero dos empregados formais e sua evolução no segmento de hospedagem nos municípios pesquisados. O que se nota, em termos gerais, é que o setor hoteleiro emprega, em suamaioria, homens. No entanto, é importante destacar que a presença das mulheres tem sido significativa em todo o período nos municípios referidos,inclusive superando o registro de homensem 2000 (segundo a RAIS,nesse ano houve registro de 58\% de mulheres no segmento). Nos anos subsequentes, houve queda, mas ocorrendo registros de crescimento, ou seja, em 2004 as mulheres ocupavam 44\% das vagas e, em 2008,47\%, número acima da média nacional em todas as atividades econômicas.

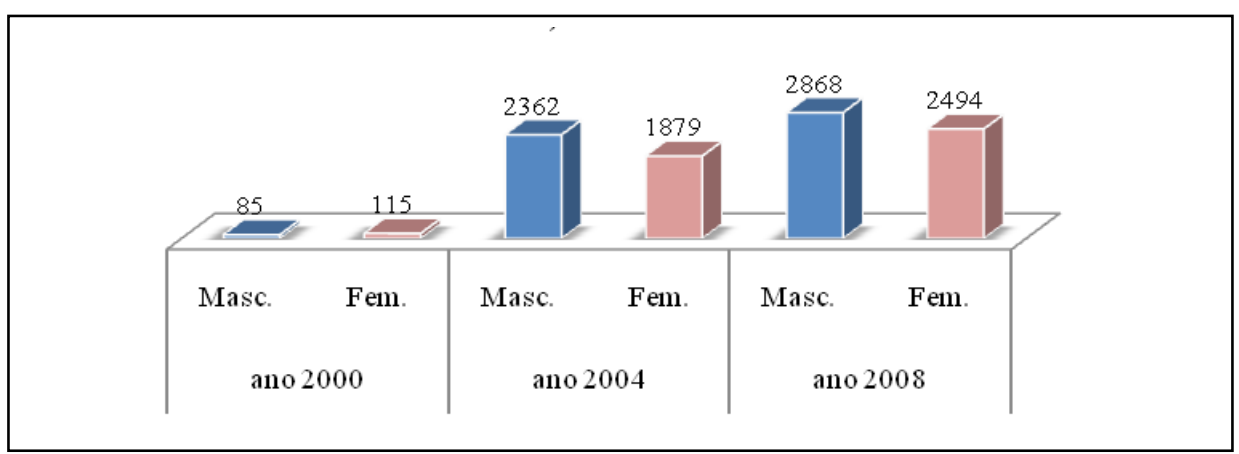

Figura 10: Evolução do Gênero dos empregados formais no subsetor de hospedagem nos municípios turísticos - 2000, 2004 e 2008.

Em termos nacionais, a RAIS indica que o crescimento do número de mulheres vem sendo gradativo nas atividades econômicas em geral. Em 2009, a participação delas foi de 41,4\%e, em 2010, foi de 41,6\%. O nível de emprego de mão de obra feminina apontou umcrescimento $7,28 \%$, superior ao registrado para os homens, que foi de $6,70 \%$ (RAIS, 2010).

Este crescimento da inserção das mulheres no mercado de trabalho se dá paralelamente à expansão do setor de serviços no Brasil. Os setores da economia ressaltados por Leone (2003), como comércio, serviços domésticos, alojamento, 
alimentação, serviços auxiliares da atividade econômica e atividades sociais (saúde, educação, previdência e assistência social) foramos principais responsáveis pelo aumento do emprego feminino nos últimos anos. Segundo a autora, nem todas as atividades contribuíram para esse aumento, mas, ao contrário, reduziram a inserção da mulher ${ }^{6}$.

No caso do estado de Goiás, entre os municípios desta análise,os que mais se destacaram na contratação de mulheres no setor de hospedagem foram Goiânia e Rio Quente. O município de Goiânia apresentou a maior média (57,3\%) e isto pode ser explicado pela sua condição de grande cidade. Segundo Leone (2003), as grandes cidades e regiões metropolitanas são mais abertas ao trabalho feminino. Os municípios de Caldas Novas e Pirenópolis, no conjunto dos seus empregados, apresenta a maioria da categoria de trabalhadores masculina. Neste panorama, o caso mais expressivo é o de Pirenópolis, que registrou no período uma média de $78 \%$ de empregados do gênero masculino na rede de hotéis e pousadas, como demonstra a tabela 1.

Tabela 1: Gênero dos empregados formais no subsetor de Hospedagem nos municípios turísticos - 2000, 2004 e 2008.

\begin{tabular}{|l|l|l|l|l|l|l|l|l|l|l|l|l|}
\cline { 2 - 12 } Municípios & \multicolumn{4}{|c|}{2000} & \multicolumn{4}{c|}{$\mathbf{2 0 0 4}$} & \multicolumn{5}{c|}{2008} \\
\cline { 2 - 13 } & Masc. & $\%$ & Fem. & $\%$ & Masc. & $\%$ & Fem. & $\%$ & Masc. & $\%$ & Fem. & $\%$ \\
\hline Goiânia & 59 & $\begin{array}{l}39 \\
\%\end{array}$ & 91 & $\underline{61 \%}$ & 843 & $46 \%$ & 988 & $54 \%$ & 953 & $43 \%$ & 1.271 & $57 \%$ \\
\hline $\begin{array}{l}\text { Caldas } \\
\text { Novas }\end{array}$ & 19 & $\begin{array}{l}54 \\
\%\end{array}$ & 16 & $46 \%$ & 829 & $61 \%$ & 528 & $39 \%$ & 1.027 & $61 \%$ & 667 & $39 \%$ \\
\hline Rio Quente & 6 & $\begin{array}{l}43 \\
\%\end{array}$ & 8 & $\underline{57 \%}$ & 108 & $48 \%$ & 119 & $52 \%$ & 144 & $48 \%$ & 155 & $52 \%$ \\
\hline Pirenópolis & 1 & $\%$ & 0 & $0 \%$ & 582 & $70 \%$ & 244 & $30 \%$ & 744 & $65 \%$ & 403 & $35 \%$ \\
\hline
\end{tabular}

Segundo Leone (2003), a expansão do emprego feminino vem ocorrendo em circunstâncias econômicas que estão longe de serem as ideais para a qualidade no mercado de trabalho. Isso é bastante válido para o mercado de hotelaria, que retém boa parte de suas vagas de baixos salários para as mulheres,alocadas naquelasatividades chamadas de "ocupações tipicamente femininas". O justo seria a participação das mulheres em cargos de atividades econômicas mais amplas e diversificadas, de modo a dar-lhes o direito de ter empregos com melhores condições de trabalho e com

\footnotetext{
${ }^{6}$ Dentro do setor de serviços, são os casos dos segmentos de serviços pessoais e domiciliares e dos bancos.
} 
possibilidades de galgar outros patamares no universo dos cargos de uma empresa, concorrendo em igualdade com os homens.

\section{Escolaridade}

Um estudo do Dieese, citado por Larentes e Miyashiro (2007, p. 83) revelou que os níveis de escolarização dos trabalhadores da hotelaria são em geral muito baixos, o que significa não ser possível "pensar em qualificação sem considerar que antes é necessário garantir, no mínimo, o direito de acesso à escola de ensino fundamental e médio". Esta conclusão estende-seaos municípios aqui pesquisados, uma vez que há predomínio de empregados com ensino médio completo apenas nos municípios de Goiânia e Rio Quente. O caso de Caldas Novas é o mais preocupante, visto que parte bem importante dos trabalhadores formais da hotelaria não completou sequer o ensino fundamental. Também em Pirenópolis o número de trabalhadores com ensino fundamental e médio completos se deu na mesma proporção. $O$ número de trabalhadores com ensino superior completo é tímido em todos os municípios turísticos, sendo que o caso que mais se distancia desta realidade é o de Rio Quente, que se manteve em igualdade com a capital, Goiânia (Figura 11).

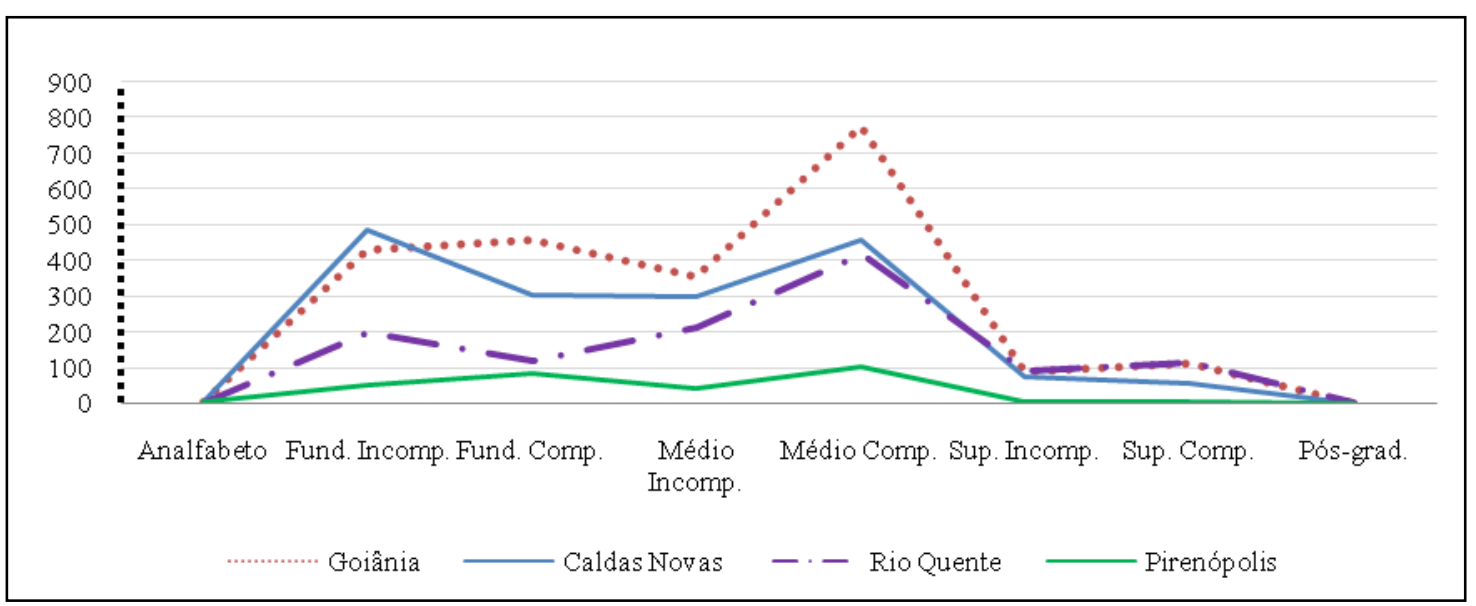

Figura 11 - Escolaridade dos empregados dos meios de hospedagem nos municípios turísticos (2008)

O fator educacional, quando em níveis baixos, representa uma problemática social que reflete na economia, uma vez que seu papel na vida do trabalhador tem 
múltiplos efeitos, tal como se segue:

[...] a educação não apenas oferece uma melhor inserção no mercado de trabalho, mas, também, proporciona alguma proteção contra oscilações de curto prazo no desempenho da economia. [...] a contribuição da educação para o bem-estar é dupla: primeiro, ao permitir o acesso a maiores salários em um determinado instante de tempo e, segundo, por reduzir o grau de incerteza sobre o futuro de rendimentos do trabalho. (RAMOS, 1993, p. 59$60)$.

Ramos (1993, p. 59-60) destaca que uma distribuição mais uniforme de escolaridade dos brasileiros poderá contribuir para redução das desigualdades tanto estáticas quanto dinâmicas. Ao relacionar este aspecto com o presente estudo, julga-se que nenhum município se aproxima desta uniformização de escolaridade. Ainda ocorrem muitos registros de empregados com ensino fundamental incompleto.

\section{Rendimento}

Há um fato que não se pode negar: a educação reflete diretamente na qualidade do trabalho e na melhoria dos rendimentos dos trabalhadores. Pelo conjunto dos gráficos sobre o rendimento médio dos trabalhadores nos municípios turísticos (Figura 12), nota-se que há uma simetria entre Goiânia, Caldas Novas e Pirenópolis em relação ao predomínio dos trabalhadores que receberam, em 2008, na faixa de 1,01 e 1,5 salários mínimos, ou seja, 59,2\%; 55,7\% e 57,8\%, respectivamente.

Em situação diversa encontra-se o município de Rio Quente, cuja faixa predominante de salário dos empregados no setor é de 2,01 a 3 salários mínimos $(34,5 \%)$, além do fato de possuir a maior diversidade de ganhos, chegando a ter o maior número de trabalhadores empregados nas atividades de alojamento recebendo acima de 10 salários mínimos (Rio Quente 22; Goiânia 6; Caldas Novas 4 e Pirenópolis 1). 

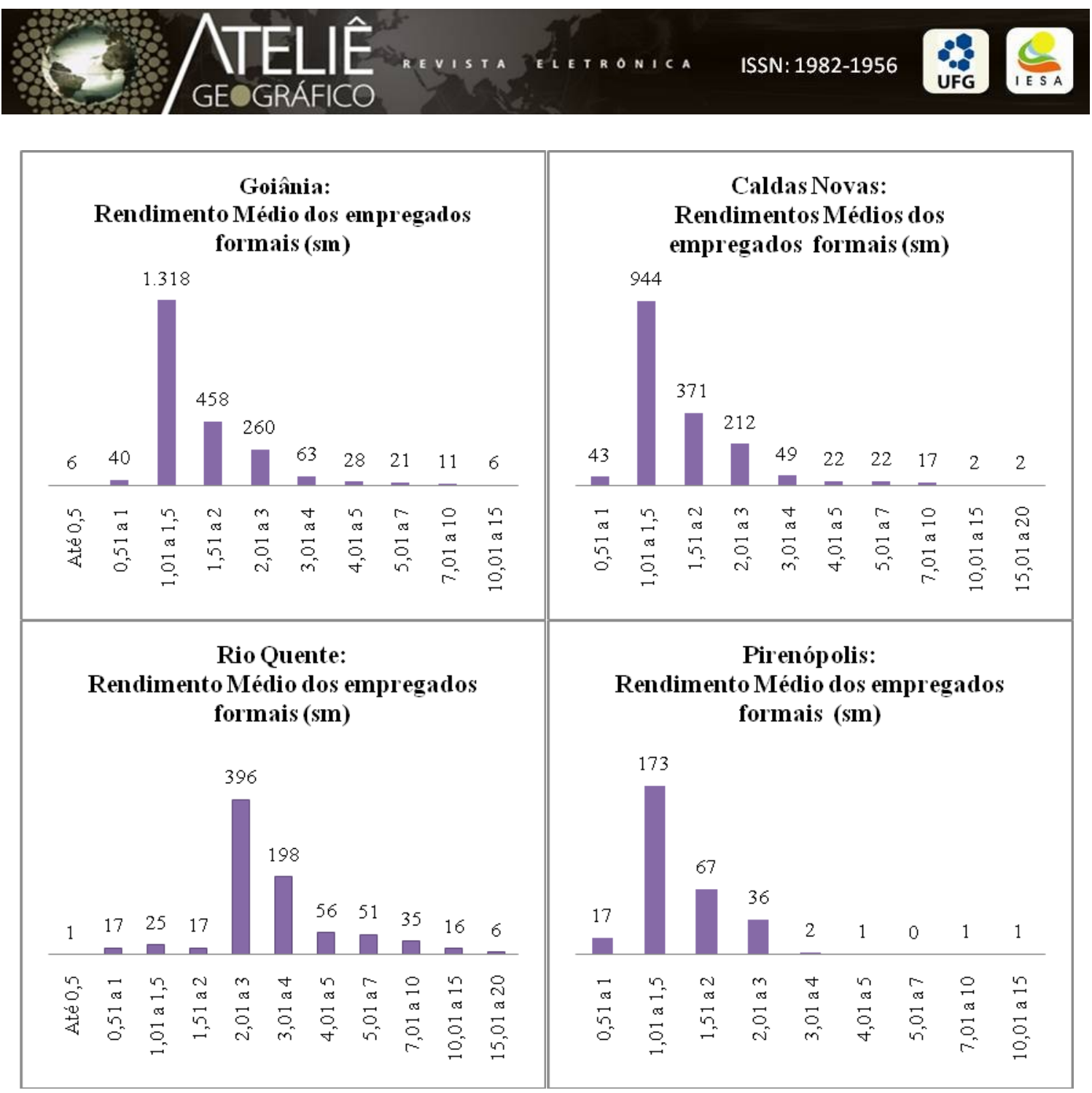

Figura 12: Rendimento médio dos empregados formais (sm) em Goiânia, Caldas Novas, Rio Quente e Pirenópolis.

É preciso considerar que, em linhas gerais, os trabalhadores do setor de hospedagem recebem pouco e isso se deve, possivelmente, à supremacia dos cargos reconhecidos como de baixa remuneração em todo o Brasil, quais sejam: recepcionista, camareiro, cozinheiro etc, que não exigem empregados com muitos anos de estudo. Em contrapartida, quem tem mais escolaridade não se submete a uma baixa remuneração. Para se ter uma ideia, a remuneração média de um camareiro de hotel, em 2008, em Goiânia, foi de R\$ 446,44; em Caldas Novas, R\$ 496,11; em Pirenópolis, R\$ 485,78 e em Rio Quente, R\$633,66. O mesmo ocorrena profissão de recepcionista de hotel, que girou em torno de $\mathrm{R} \$ 443,24$ a $\mathrm{R} \$ 603,13$, sendo que os trabalhadores de Pirenópolis receberam o menor valor e os de Rio Quente o maior (CAGED, 2008).

Os baixos níveis de rendimento dessas profissões permitem ampliar o número de 
vagas de emprego nos municípios turísticos. Em Rio Quente, segundo o Cadastro Geral de Empregados e Desempregados (CAGED, 2008), os cargos que mais contrataram em 2008 foram na área de alimentos e bebidas (cozinhador de frutas e verduras e garçom) e na hotelaria (recepcionista em geral, porteiro de hotel, camareiro de hotel, assistente administrativo e recepcionista de hotel). Analogamente, em Caldas Novas, os cargos que mais empregaram foram: servente de obras, vendedor de comércio varejista, cozinheiro, auxiliar de escritório, garçom, camareiro de hotel etc. Em Pirenópolis os cargos de camareiro, recepcionista e cozinheiro posicionaram-se a partir do $7^{\circ}$ lugar. Atipicamente, estas profissões não apareceram entre as que mais contratam em Goiânia. Exceto pelo atendente de lanchonete, em $10^{\circ}$ lugar e pelo cozinheiro, em $14^{\circ}$.

O IPEA (2008) apresenta um fato complicador para todas as ACT. Segundo o estudo, "as remunerações médias do turismo são $20 \%$ inferiores à média global, tendo diminuído de 79,9\%, em dezembro de 2002, para 78,5\%, em 2007”, e completa dizendo que este quadro pode apresentar uma participação declinante no total das remunerações de todos os setores da economia.

\section{Considerações Finais}

Os meios de hospedagem constituem um subsetor essencialmente turístico, juntamente com as agências de viagem e o aluguel de transportes. Por esse aspecto, é mais viável uma análise dos impactos da atividade a partir destes equipamentos em municípios turísticos. Este artigo chegou às seguintes conclusões:

O setor do turismo, nos municípios de Goiânia, Caldas Novas, Pirenópolis e Rio Quente, é um grande empregador e o segmento de hospedagem é o que melhor aloca os trabalhadores formais. No entanto, ainda se configura como uma atividade pouco profissionalizada quando se trata de nível de escolaridade e rendimento médio dos empregados. O salário não é um fator que incentiva o trabalho no turismo, assim como já ressaltou Zamboni (2004 apud WEGRZYNOVSKI, 2007) em outro estudo sobre o turismo como mercado de trabalho.Cumpre ressaltar que esta ainda é uma situação padrão do setor do turismo em todo o país, segundo o Ministério do Turismo e a EMBRATUR (2007). Ou seja, de maneira geral, o setor registra baixos níveis de remuneração e os meios de hospedagem e alimentação são as categorias que menos 
valorizam seus empregados. Não por mera coincidência, estes dois segmentos são responsáveis pelos maiores estoques de empregos celetistas, como é o caso dos municípios de Rio Quente, Caldas Novas e Pirenópolis. Das variáveis analisadas idade, escolaridade e rendimento - ficou evidente que, dos municípios estudados, Goiânia se comporta de modo assimétrico em todos os aspectos. No contexto das ACT, em termos proporcionais, o setor de hospedagem representa em torno de $8 \%$ dos empregados no turismo, mesmo tendo este segmento o maior número de trabalhadores do estado de Goiás (2.224). Nos demais municípios, os meios de hospedagem configuram os maiores empregadores do setor.

Um caso que chamou atenção foi o do município de Rio Quente, dado o seu maior nível de profissionalização, revelado em termos de níveis de escolaridade e rendimentos mais altos, maior diversificação na idade e maior inserção do trabalho feminino. Neste último quesito, ele só perde para Goiânia, município que mais acomoda o trabalho feminino, haja vista sua condição de capital. Já o município de Pirenópolis representou exatamente o oposto neste ponto: seus empregados são essencialmente do gênero masculino. Nos demais itens analisados, notou-se ainda que o setor de hospedagem concentra os empregados com a menor diversificação de salários e níveis de escolaridade.

No conjunto dos municípios, verificou-se que o setor de hospedagem, pela ótica dos índices obtidos entre seus empregados, ainda precisa profissionalizar e valorizar seus recursos humanos, sobretudo se observada a pouca evolução nos dados de 2004 para 2008. É preciso considerar que o setor de serviços é o quemais cresce na economia e representa o maior gerador de empregos, sobretudo nas grandes e médias cidades e nosmunicípios turísticos. Todavia, por se tratar do setor de serviços, sua "matériaprima" são as pessoas, sua produtividade, sua formação, sua qualificação, que estão paripassua seus níveis de rendimento. Este item, por sinal, representa, se não o maior, o mais importante incremento da qualidade e da profissionalização dos serviços prestados ao público viajante.

Com esta pesquisa pretendeu-se focar o grupo de trabalhadores do setor do turismo, sobremaneira dos de hospedagem, traçando seu perfil, de modo a conhecer suas realidades, vislumbrando uma reconfiguração da atual situação. 


\section{Referências bibliográficas}

BRASIL. INSTITUTO DE PESQUISA ECONÔMICA APLICADA (IPEA). Estimativas da mão de obra formal ocupada em atividades características do turismo, para 20 municípios indutores do turismo, dezembro de 2002 e setembro de 2008. Disponível em:

http://www.ipea.gov.br/portal/images/stories/17_estimativas_da_mao_de_obra_formal_ ocupada_emacts_para_20_municipios_novembro_2008.pdf

. Estimativas referentes ao rendimento médio da ocupação formal em atividades características do turismo, com base em dados da GFIP. Brasília, 2008. Disponível em:

http://www.ipea.gov.br/portal/images/stories/16_estimativas_do_rendimento_medio_da _ocupacao_formal_outubro_2008.pdf

MINISTÉRIO DO TRABALHO E EMPREGO (MTE). Relação Anual de Informações Sociais (RAIS). Brasília, 2004 e 2008. Disponível em: http://portal.M.T.E.gov.br/portal-mte/

Características do Emprego Formal - RAIS 2010: Principais Resultados. Brasília, 2010. Disponível em:

http://www.mte.gov.br/rais/2010/arquivos/Apresentacao.pdf

Características do Emprego Formal - RAIS 2009: Principais Resultados. Disponível em: http://www.mte.gov.br/rais/resultado_2009.pdf.

Cadastro Geral de Empregados e Desempregados - CAGED. Brasília,2008. Disponível em:

http://perfildomunicipio.caged.gov.br/index.asp?entrada=perfildomunicipio

- MINISTÉRIO DO TURISMO/EMBRATUR. Plano Nacional de Turismo:uma viagem de inclusão, 2007-2010. Brasília, 2007. Disponível em: http://www.turismo.gov.br/turismo/o_ministerio/plano_nacional/

CARVALHO, Gisélia Lima. Turismo e geração de empregos formais: um estudo sobre os municípios indutores do turismo do estado de Goiás.Boletim Goiano de Geografia/BGG. Goiânia: IESA/UFG, 2011.Disponível em:

http://www.revistas.ufg.br/index.php/bgg/article/view/15403/9602

COOPER, Cris e et al. Turismo: princípios e práticas. Trad. Alexandre Salvaterra. 3.ed. Porto Alegre: Brookman, 2007.

GODINHO, Rangel G.; OLIVEIRA, Ivanilton J. de. Análise e avaliação da distribuição geográfica da infraestrutura turística no sítio histórico de Pirenópolis (GO): subsídios ao planejamento turístico. Boletim Goiano de Geografia/BGG. Goiânia: IESA/UFG, 2010. Disponível em: http://www.revistas.ufg.br/index.php/bgg/article/view/11198

LARENTES, Adriano da S; MIYASHIRO, Rosana. Turismo e hospitalidade no 
Brasil: um estudo sobre os trabalhadores da hotelaria. São Paulo: CUT, 2007. Disponível em:

http://www.escoladostrabalhadores.org.br/turismo_e_hospitalidade_no_brasil_estudo_h otelaria.pdf

LEONE, Eugênica T. O trabalho da mulher nas regiões metropolitanas brasileiras. In: PRONI, M. W. \& HENRIQUE, W. (Orgs.). Trabalho, Mercado e Sociedade:o Brasil nos anos 90. São Paulo: Unesp, 2003.

ORGANIZAÇÃO MUNDIAL DO TURISMO - OMT. Introdução ao turismo. Trad. Dolores Martins R. Corner. São Paulo: Roca, 2001.

RAMOS, Lauro. A distribuição de rendimentos no Brasil: 1976/1985. Rio de Janeiro: Ipea, 1993.

WEGRZYNOVSKI, Ricardo. Desvendando um setor socialmente importante.Revista desafios do Desenvolvimento. Brasília: IPEA, 2007. Disponível em: http://desafios2.ipea.gov.br/003/00301009.jsp?ttCD_CHAVE=3255

ZAMBONI, Roberto Aricó; CAMARGO, Reinaldo Soares. Uma leitura dos impactos da crise sobre o setor turismo a partir das estimativas de emprego no setor. Brasília: IPEA, 2010.

Disponível em: http://www.ipea.gov.br/portal/images/stories/BoletimDirur7-09.pdf

Recebido para publicação em outubro de 2011.

Aprovado para publicação em janeiro de 2012. 